\title{
BMJ Open Has the role of personal income in alcohol drinking among teenagers changed between 1983 and 2013: a series of nationally representative surveys in Finland
}

Tomi Lintonen, ${ }^{1,2}$ Jaakko Nevalainen ${ }^{2}$

To cite: Lintonen $\mathrm{T}$, Nevalainen J. Has the role of personal income in alcohol drinking among teenagers changed between 1983 and 2013: a series of nationally representative surveys in Finland. BMJ Open 2017;7: e013994. doi:10.1136/ bmjopen-2016-013994

- Prepublication history for this paper is available online. To view these files please visit the journal online (http://dx.doi.org/10.1136/ bmjopen-2016-013994).

Received 23 August 2016 Revised 7 February 2017 Accepted 17 February 2017

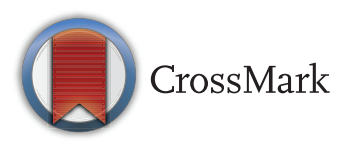

${ }^{1}$ Finnish Foundation for Alcohol Studies, Helsinki, Finland

${ }^{2}$ University of Tampere, School of Health Sciences, Tampere, Finland

Correspondence to Dr Tomi Lintonen; tomi.lintonen@ alkoholitutkimussaatio.fi

\section{ABSTRACT}

Objective: Affordability is known to be a key determinant of alcohol consumption, possibly even more important in adolescence. Relating adolescent drinking pattern developments over a period of time to trends in adolescent income can yield information on the significance of parental control of adolescent income.

Design: Biannual repeated cross-sectional surveys. Setting: Nationally representative samples.

Participants: 14-year-old adolescents in the period 1983-2013 in Finland ( $\mathrm{N}=33$ 771).

Results: Adolescents' alcohol drinking pattern was significantly associated with their disposable income. The OR for monthly drunkenness versus abstinence was $6.6(95 \% \mathrm{Cl} 5.0$ to 8.8$)$ among girls and 9.0 (6.3 to 13.0) among boys in the highest income group compared with the lowest. However, the association between income and drinking pattern weakened considerably during the 30-year period.

Conclusions: Disposable income has been a significant predictor of adolescent alcohol drinking in the past 30 years. However, in the recent years, the amount of disposable money has decreased in importance.

\section{INTRODUCTION}

At the population level, the price of alcohol is known to be a key determinant of alcohol drinking intensity. ${ }^{12}$ It can be assumed that affordability is even more important in adolescence since their purchasing power is significantly lower than in adulthood. In the quest for determinants of adolescent drinking, ${ }^{3}$ it may thus be useful to look at the issue of alcohol affordability among teenagers. In fact, changes over time in adolescent disposable income have been shown to be associated with adolescent drinking trends. ${ }^{4}$ While population income changes tend to be relatively slow, changes in

\section{Strengths and limitations of this study}

- Large nationally representative samples.

- Thirty-year time series with the timing of the study, sampling and data collection method similar throughout the study period.

- Possible measurement bias due to self-reported indicators.

- The response rate declined over the years from $83 \%$ in 1983 to $38 \%$ in 2013 .

- The use of real income that accounts for the effects of inflation.

adolescent income follow a different logic. ${ }^{5}$ Furthermore, drinking large amounts of alcohol until drunk seems more affected by so-called period effects (eg, macroeconomic changes, alcohol price changes) than drinking small amounts. ${ }^{6}$

The proportion of Finnish 14-year-olds reporting that they do not drink alcoholic beverages decreased from $60 \%$ in the early 1980 s to around $30 \%$ in $1997-1999$, but increased again to over $60 \%$ in $2013 .^{7}$ At the other end of the drinking pattern spectrum, the proportion of 14-year-olds drinking until drunk at least once a week has stayed between $0 \%$ and 2\% during the 30-year period from 1983 to 2013 . The most notable changes have been observed in the proportion of 14-year-olds drinking until drunk at least once a month. Both in the early 1980s and early 2010s, around 5\% of 14-year-old girls and boys drank until drunk at least monthly. However, in the peak year of 1999, $16 \%$ of girls and $11 \%$ of boys reported drinking until drunk at least once a month. ${ }^{8}$ Similar findings on recent decreases in adolescent drinking have been observed in the UK, ${ }^{9}$ the USA, ${ }^{10}$ Sweden, ${ }^{11}$ Australia ${ }^{12}$ and many other high-income countries. ${ }^{13}$ 
While several factors associated with adolescent alcohol initiation have been studied, ${ }^{14}{ }^{15}$ adolescent disposable income has received little research interest, although it potentially has significant implications for substance use. Recently, the Institute of Alcohol Studies in the UK explored potential explanations for declining youth drinking and wound up focusing heavily on affordability. ${ }^{16}$ Even though the legal alcohol purchase age is 18 years in Finland, adolescents widely report that it is easy to purchase alcoholic beverages. ${ }^{17}{ }^{18} \mathrm{In}$ addition, the underaged have the option of asking older friends to purchase the beverages using their money.

Adolescents' disposable income in western countries is typically received as allowances, gifts from parents and relatives, or from household work and external part-time work. $^{5}{ }^{19}{ }^{20}$ In the USA in 1997, around half of those aged 14-15 years were employed at least part time. ${ }^{21}$ In the Nordic countries, a survey by Danske Bank in 2012 reported that $19 \%$ of those aged 15-17 years earned money from work outside the family. ${ }^{22}$ Very few studies have analysed income among young people who still live at home or the sociodemographic determinants affecting income. ${ }^{19} 20$ Macro-level determinants include changes in the national economy and in cultural norms. In an economic downturn, teenagers find it harder to get part-time jobs because of the higher level of general unemployment. ${ }^{23} 24$ Micro-level determinants include age, gender, family type, place of residence, income and the socioeconomic status of the family. ${ }^{25}$ Interestingly, adolescents from disadvantaged backgrounds may have more money at their own disposal than young people from better-off families. ${ }^{20} 26$ In Finland, adolescents from single-parent families seem to have significantly higher income than those from nuclear families when adjusting for other family socioeconomic indicators. ${ }^{5}$

In Finland, the disposable income of 14-year-olds has generally increased from around $€ 6$ in 1983 to $€ 12$ per week in 2013, with a slight decrease in the early 1990s associated with an economic depression ${ }^{25}$ (figures were adjusted for money value changes). In the 1980s, boys aged 14 years had roughly 5\% more money at their disposal than same-aged girls, but this gender gap widened to around $10 \%$ in the 2010 s. In fact, studies have suggested that gender is more significant in explaining teenagers' incomes than socioeconomic indicators like family background or place of residence. ${ }^{5} 27$

Family background may play an important role in alcohol drinking and disposable income among adolescents. More drinking among adolescents from families with less educated parents has been identified; ${ }^{4} 28$ however, an opposing observation has been reported. ${ }^{29}$ No differences in disposable income among Finnish 14-year-olds by parental education or professional status were observed in a recent study. ${ }^{25}$ All in all, it seems that when studying the drinking and income of 14-year-olds, family background must be taken into account.

Since 14-year-olds receive their income mainly from their parents, income may serve as a way to control their offsprings' drinking. More insight into how disposable income affects adolescent drinking can be obtained by looking at adolescent drinking pattern developments over a period of time, and relating the trends to changes in adolescent income. The current paper examines associations between alcohol drinking and income among Finns aged 14 years in a 30-year period from 1983 to 2013. Since previous research ${ }^{30}{ }^{31}$ has shown that, in addition to drinking alcoholic beverages per se, drinking until drunk is a significant determinant of problems among adolescents, the whole spectrum of drinking from abstinence to weekly drunkenness is analysed here.

\section{METHODS}

The study data were derived from a nationwide monitoring system of adolescent health behaviours in Finland, the Adolescent Health and Lifestyle Survey (AHLS). ${ }^{7}$ Self-administered questionnaires were mailed to mutually independent, nationally representative samples of teenagers; for the current study, we selected those aged 14 years, as previous research has indicated that changes in drinking patterns have been largest in this age group. ${ }^{6}$ Two or, recently, three reinquiries were sent to non-respondents. In addition to the paper questionnaire, a digital version was available on the internet in 2009, 2011 and 2013. Samples were obtained from the National Population Register Center and were based on particular dates of birth, so that all Finns born on the sample days were included.

All procedures performed in the study were in accordance with the ethical standards of the institutional research committees and with the 1964 Helsinki declaration and its later amendments or comparable ethical standards. The survey series originated from 1977 and extends to the year 2013. Each data collection year, the study plan and data collection procedure were reviewed by ethics committees. In the early years, the Ethics Committees of the Department of Public Health at the University of Helsinki and the Pirkanmaa Hospital District, Finland, approved the study protocol. Recently, the Ethics Committee of the Tampere region (Finland) approved the study protocol: filling in the questionnaire was considered as adolescents' consent to participate. No parental consent was requested. In case the respondent's parents wished to inspect the questionnaire, the respondent was instructed to present the questionnaire to his/her parents before answering the questions.

The mean age of respondents was 14.6 years. Data were collected from February to April every other year. The timing of the study, sampling and data collection method were similar throughout the study period. Sample sizes varied; the numbers of respondents ranged from 3105 in 1989 to 8390 in 1997, while response rates varied from $83 \%$ in 1983 to $47 \%$ in 2011 and $38 \%$ in $2013 .^{7}$ The response rates were higher among girls. Altogether, 15761 boys and 18010 girls responded to the surveys. 
The questionnaire consisted of 12 pages each year. The majority of the questions remained unchanged throughout the years. The frequency of alcohol use was investigated with the question 'How often do you use alcohol? Try to include also those times you consumed only small amounts of alcohol'. The alternatives were 'daily', 'a few times a week', 'once a week', 'a few times a month', 'about once a month', 'about once in 2 months', '3-4 times a year', 'once a year or less frequently', 'I do not use alcohol'. Drunkenness was measured with the question 'How often do you use alcohol until you are really drunk?' The alternatives were 'once a week or more often', 'once or twice a month', 'less frequently', 'never'. Using these two questions, an indicator for drinking patterns was constructed: non-drinker, drinks only small amounts, drinks until drunk occasionally, drinks until drunk at least once a month, drinks until drunk at least once a week. The measures for drunkenness have been found to be reasonably reliable and valid. ${ }^{32} 33$ The question on weekly disposable income, 'How much money do you have, on average, at your disposal per week (not including housing, food and clothing expenses)?', was kept exactly the same throughout the years. The response categories, however, were changed to reflect changes in monetary value and the adoption of the euro in 2002. The responses were transformed into 2013 euro using the cost-of-living index provided by Statistics Finland.

The yearly distributions of all the variables are shown in table 1 . The proportion of items missing data in the outcome variable (drinking style) was $1.7 \%$ while $2.8 \%$ of the responses were missing for the main explanatory variable (disposable income). Between $1 \%$ and $3 \%$ of the information was missing in the other explanatory variables, but ranged from $4 \%$ to $11 \%$ by study year in the case of the father's education. In the regression models, the ORs for the group with missing data on father's education most resembled the group with lowest education. Individuals with missing data on any of the indicators were excluded from the models. The effective sample sizes were 13543 for boys and 15731 for girls, $87 \%$ of the survey response.

Separate multinomial regression models were constructed for the genders to predict the five-category drinking pattern indicator; abstinence was used as the reference category. Study year and quadratic study year terms were used as continuous explanatory variables accounting for time trends. The income variable contained six categories and the lowest category ( $€ 2$ per week or less) served as the reference category. Interaction terms between income and time variables were also entered into the models to study possible differential changes in time by income categories. In the next step, family background variables were entered into the models. In order to study the interaction between income and time further, the strength of the association was studied by cross-tabulating income with the drinking pattern variable separately for each study year. A $\gamma$ coefficient ${ }^{34}$ with $95 \%$ CIs is shown for these associations for each year. Next, a simple regression of the $\gamma$ coefficient on survey year was performed. The $\gamma$ coefficient is an overall measure of association between two ordinal variables, and can be interpreted much like the ordinary linear correlation coefficient.

A set of potential confounders was included in regression models. The family structure is an indicator of whether or not the respondent currently lives with his or her parents (nuclear family vs non-nuclear family). The place of residence is a combined indicator bringing together sample-based (population registry) and selfreported information (metropolitan areas/cities/towns/ villages/rural areas). Self-reported data on the father's or guardian's education was classified into basic (9 years or less), secondary (9-12 years) and tertiary (over 12 years). The father's or guardian's professional status was coded from open-ended responses: ${ }^{35}$ upper white collar, lower white collar, agriculture and forestry, blue collar.

Finally, we conducted two separate sensitivity analyses: one for investigating the sensitivity of the $\gamma$ coefficient to the changes in the income distribution and the second for assessing the sensitivity of the model to alcohol price changes. In the first analysis, we aggregated the lowest and highest income categories so that, in each study year, the lowest and highest income category included as close to $20 \%$ of the total number of respondents as possible. In the second analysis, the yearly real price indices of alcoholic beverages, which were available for the year 2000 onwards, were added as covariates into the models. When testing for the role of alcohol price changes, we first ran gender-specific models with years 2001-2013 without the price indices, and then compared the corresponding models with the indices added. IBM SPSS Statistics software was used for the analyses.

\section{RESULTS}

Alcohol drinking and drunkenness increased among both girls and boys in all income groups from 1983 to the late 1990s, after which it decreased (figure 1). Weekly drunkenness in the lowest income group (€2 per week or less) was non-existent throughout the period 1983-2013 and monthly drunkenness was rare. In the highest income group ( $€ 17$ or more per week), around $40 \%$ of girls and boys drank until drunk at least occasionally in the study period of 1983 until the late 1990s, after which drunkenness decreased considerably. The proportion of 14-year-olds who drank alcoholic beverages but never until drunk stayed largely unchanged throughout the study period.

Both time and quadratic time were statistically significant predictors in the model when predicting monthly drunkenness, occasional drunkenness and drinking of small amounts of alcoholic beverages; non-drinkers formed the reference group (table 2). Weekly disposable income predicted drunkenness and drinking only small 
Table 1 Distributions of all variables used in the study by the year of data collection

\begin{tabular}{|c|c|c|c|c|c|c|c|c|c|c|c|c|c|c|c|c|c|}
\hline & & 1983 & 1985 & 1987 & 1989 & 1991 & 1993 & 1995 & 1997 & 1999 & 2001 & 2003 & 2005 & 2007 & 2009 & 2011 & 2013 \\
\hline \multicolumn{18}{|l|}{ Gender } \\
\hline Boys & $\%$ & 48 & 48 & 48 & 47 & 46 & 46 & 46 & 45 & 47 & 45 & 45 & 42 & 41 & 42 & 40 & 45 \\
\hline Girls & $\%$ & 52 & 52 & 52 & 53 & 54 & 54 & 54 & 55 & 53 & 55 & 55 & 58 & 59 & 58 & 60 & 55 \\
\hline \multicolumn{18}{|l|}{ Alcohol use } \\
\hline Drunk weekly & $\%$ & 0 & 0 & 1 & 1 & 1 & 1 & 1 & 2 & 2 & 1 & 1 & 1 & 1 & 0 & 0 & 0 \\
\hline Drunk monthly & $\%$ & 4 & 3 & 5 & 7 & 8 & 10 & 8 & 11 & 11 & 9 & 6 & 5 & 4 & 5 & 3 & 2 \\
\hline Drunk occasionally & $\%$ & 17 & 13 & 19 & 20 & 20 & 22 & 23 & 25 & 23 & 21 & 18 & 16 & 13 & 15 & 14 & 10 \\
\hline Drinks but not until drunk & $\%$ & 28 & 25 & 27 & 26 & 30 & 28 & 31 & 28 & 31 & 29 & 30 & 26 & 22 & 27 & 21 & 21 \\
\hline Does not drink & $\%$ & 50 & 58 & 46 & 45 & 39 & 38 & 36 & 33 & 32 & 35 & 43 & 50 & 60 & 53 & 61 & 66 \\
\hline Missing & $\%$ & 1 & 1 & 2 & 1 & 1 & 2 & 1 & 1 & 2 & 5 & 3 & 3 & 0 & 1 & 1 & 0 \\
\hline \multicolumn{18}{|l|}{ Weekly disposable income } \\
\hline$€ 17$ or more & $\%$ & 2 & 4 & 7 & 4 & 5 & 4 & 5 & 6 & 8 & 7 & 11 & 9 & 13 & 16 & 21 & 20 \\
\hline$€ 10-€ 16$ & $\%$ & 5 & 6 & 12 & 9 & 13 & 11 & 12 & 13 & 13 & 14 & 19 & 17 & 20 & 25 & 27 & 27 \\
\hline$€ 7-€ 9$ & $\%$ & 11 & 17 & 18 & 16 & 19 & 18 & 17 & 18 & 19 & 18 & 14 & 12 & 12 & 12 & 13 & 11 \\
\hline$€ 5-€ 6$ & $\%$ & 24 & 30 & 30 & 22 & 24 & 22 & 21 & 23 & 21 & 19 & 26 & 28 & 26 & 22 & 19 & 19 \\
\hline$€ 3-€ 4$ & $\%$ & 34 & 26 & 20 & 26 & 21 & 24 & 24 & 22 & 22 & 20 & 17 & 18 & 15 & 12 & 11 & 8 \\
\hline$€ 2$ or less (reference) & $\%$ & 23 & 16 & 10 & 20 & 16 & 19 & 18 & 17 & 16 & 15 & 12 & 15 & 13 & 9 & 7 & 10 \\
\hline Missing & $\%$ & 1 & 2 & 4 & 2 & 2 & 2 & 2 & 1 & 2 & 7 & 2 & 2 & 2 & 4 & 4 & 6 \\
\hline \multicolumn{18}{|l|}{ Place of residence } \\
\hline Metropolitan area & $\%$ & 10 & 10 & 9 & 11 & 10 & 9 & 11 & 11 & 10 & 14 & 16 & 16 & 16 & 15 & 16 & 14 \\
\hline Cities & $\%$ & 17 & 16 & 17 & 16 & 15 & 15 & 15 & 16 & 16 & 16 & 15 & 15 & 15 & 15 & 14 & 18 \\
\hline Towns & $\%$ & 27 & 27 & 33 & 29 & 33 & 32 & 35 & 35 & 33 & 31 & 32 & 33 & 31 & 33 & 34 & 32 \\
\hline Villages & $\%$ & 27 & 28 & 26 & 26 & 26 & 26 & 22 & 23 & 24 & 20 & 21 & 20 & 22 & 20 & 19 & 20 \\
\hline Rural areas & $\%$ & 19 & 17 & 14 & 16 & 15 & 16 & 16 & 15 & 15 & 15 & 15 & 15 & 16 & 16 & 16 & 15 \\
\hline Missing & $\%$ & 0 & 2 & 1 & 1 & 2 & 2 & 1 & 1 & 2 & 4 & 2 & 2 & 1 & 1 & 1 & 2 \\
\hline \multicolumn{18}{|c|}{ Father's/guardian's education } \\
\hline Basic & $\%$ & 78 & 72 & 70 & 65 & 63 & 61 & 56 & 57 & 59 & 54 & 57 & 51 & 54 & 45 & 52 & 48 \\
\hline Secondary & $\%$ & 12 & 13 & 12 & 13 & 15 & 17 & 18 & 15 & 13 & 13 & 12 & 14 & 12 & 11 & 12 & 11 \\
\hline Tertiary & $\%$ & 10 & 11 & 13 & 16 & 17 & 18 & 20 & 23 & 21 & 23 & 25 & 28 & 33 & 41 & 37 & 40 \\
\hline Missing & $\%$ & 0 & 4 & 5 & 6 & 5 & 5 & 6 & 5 & 6 & 11 & 5 & 7 & 0 & 2 & 0 & 1 \\
\hline \multicolumn{18}{|c|}{ Father's/guardian's professional status } \\
\hline Upper white collar & $\%$ & 15 & 16 & 18 & 21 & 22 & 22 & 24 & 24 & 34 & 36 & 33 & 34 & 36 & 39 & 40 & 43 \\
\hline Lower white collar & $\%$ & 25 & 25 & 27 & 27 & 27 & 29 & 29 & 29 & 22 & 20 & 24 & 25 & 23 & 23 & 16 & 17 \\
\hline Agriculture and forestry & $\%$ & 13 & 11 & 10 & 9 & 9 & 7 & 6 & 6 & 7 & 6 & 6 & 6 & 6 & 4 & 6 & 6 \\
\hline Blue collar & $\%$ & 46 & 46 & 43 & 42 & 39 & 40 & 37 & 38 & 35 & 35 & 34 & 32 & 32 & 31 & 36 & 31 \\
\hline Missing & $\%$ & 1 & 2 & 2 & 2 & 4 & 2 & 3 & 2 & 3 & 3 & 2 & 2 & 3 & 3 & 2 & 4 \\
\hline \multicolumn{18}{|l|}{ Family structure } \\
\hline Nuclear family & $\%$ & 80 & 79 & 78 & 79 & 77 & 77 & 76 & 75 & 74 & 73 & 75 & 74 & 76 & 76 & 79 & 78 \\
\hline Non-nuclear family & $\%$ & 19 & 20 & 21 & 20 & 23 & 22 & 24 & 24 & 25 & 24 & 24 & 25 & 23 & 24 & 21 & 21 \\
\hline Missing & $\%$ & 1 & 0 & 1 & 0 & 0 & 1 & 0 & 1 & 1 & 3 & 1 & 1 & 0 & 1 & 0 & 1 \\
\hline Total & $\mathrm{N}$ & 3721 & 3353 & 8113 & 3105 & 7634 & 8189 & 8382 & 8390 & 8219 & 7292 & 6761 & 6503 & 5840 & 5516 & 4566 & 3535 \\
\hline
\end{tabular}




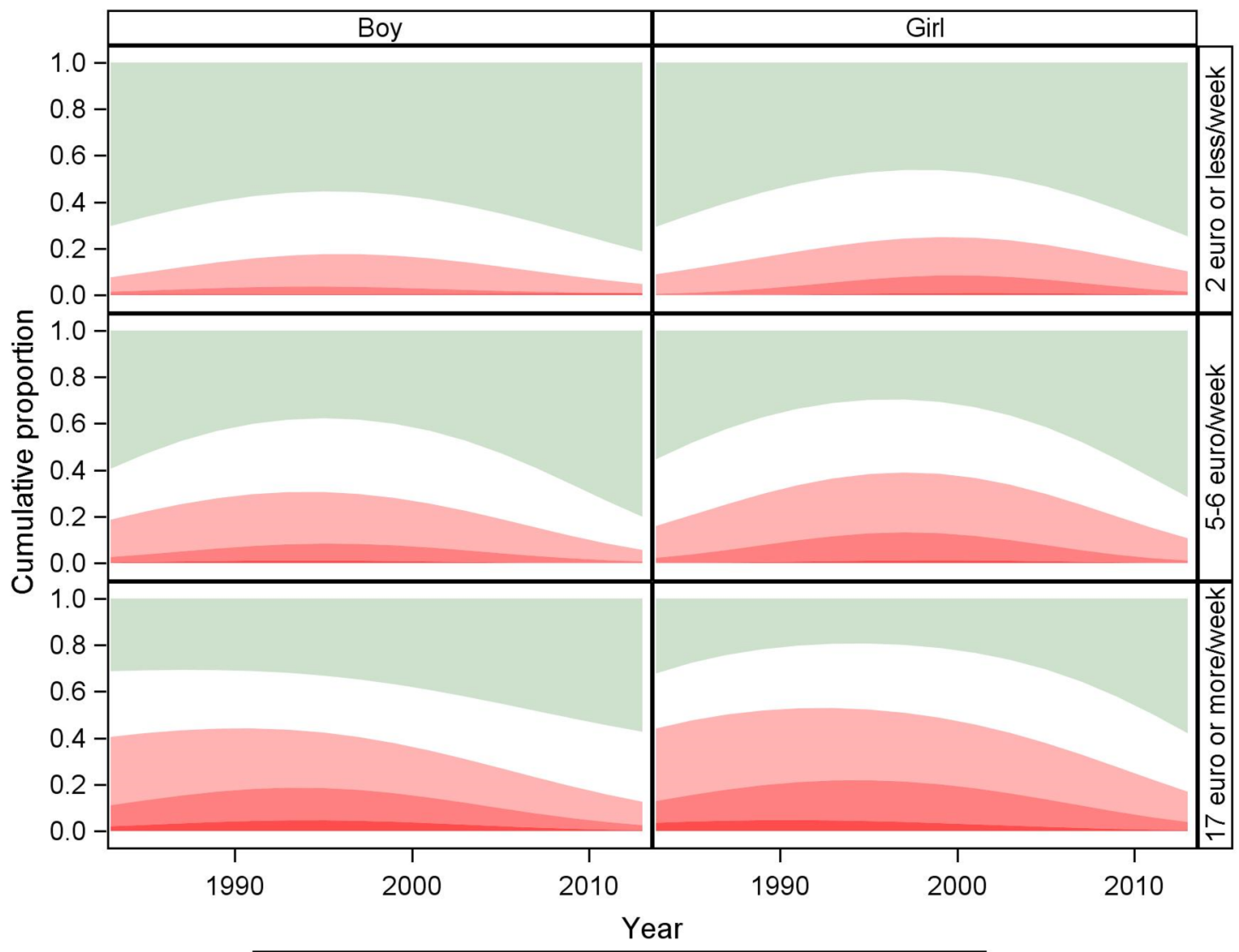

weekly $\square$ monthly $\square$ occasionally $\square$ not until drunk $\square$ never

Figure 1 Estimated alcohol drinking (weekly drunkenness, monthly drunkenness, occasional drunkenness, drinking but not until drunk, does not drink) probabilities among 14-year-olds in the period 1983-2013 in the lowest income group (€0-€2/week), the most common income group (€5-€6/week) and the highest income group (€17 or more/week).

amounts in a consistent manner: the higher the income, the higher the odds were for drinking. The interactions between money and time, and money and quadratic time were both statistically significant. This reflects the presence of non-monotonic time trends. Model-based estimated cumulative proportions (probabilities) for drinking patterns over time are displayed in figure 1.

Owing to the apparent interaction, $\gamma$ coefficients between drinking patterns and income are seen to change in time (figure 2). In the 1980s, the association was weaker in 1985 and 1987. Since 1989, the $\gamma$ coefficients generally decreased. However, the association may have been somewhat stronger in 2011 and 2013 than in the preceding three measurements. In regression models of the $\gamma$ coefficient on survey year, the estimated regression coefficient is -0.049 per 10-year interval, suggesting a declining trend $(p=0.00025)$. This is in agreement with the interaction tests reported above.

Finally, potential confounders (place of residence, father's or other guardian's education, father's or other guardian's labour market position, family type) were included in the regression models. The place of residence was generally not a statistically significant predictor for drinking patterns either among girls or boys; girls' monthly drunkenness was more probable in places other than rural areas. Low father's or other guardian's education and low father's or other guardian's labour market position were associated with slightly more severe drinking patterns. Living in a family other than one consisting of two parents was associated with significantly more severe drinking, especially among girls.

Sensitivity analysis showed that the income distribution change over the years seems not to have affected the relationship between income and drinking significantly as the $\gamma$ coefficients resulting from this were very close to the original ones presented in figure 2.

In the second sensitivity analysis, alcoholic beverage price indices were added to the models. Among both genders, the estimates for personal disposable income changed only marginally and not in a uniform direction. The estimates for the price indices were not statistically significant predictors in the models except among boys for drinking until drunk occasionally (years 2009 vs 2003: $\mathrm{p}=0.045$ ) and among girls for drinking but not until drunk (years 2007 vs 2003: $p=0.047$ ). These two are likely to be chance findings out of 56 statistical tests.

\section{DISCUSSION}

On the basis of a comparable series of nationally representative surveys in Finland since 1983, we conclude that 14-year-old adolescents' alcohol drinking became more 
Table 2 Multinomial logistic regression models for 14-year-old boys' and girls' drinking patterns.

\begin{tabular}{|c|c|c|c|c|}
\hline Boys & $\begin{array}{l}\text { Drunk weekly } \\
\text { OR } 95 \% \mathrm{Cl}\end{array}$ & $\begin{array}{l}\text { Drunk monthly } \\
\text { OR } 95 \% \mathrm{Cl}\end{array}$ & $\begin{array}{l}\text { Drunk } \\
\text { occasionally } \\
\text { OR } 95 \% \mathrm{Cl}\end{array}$ & $\begin{array}{l}\text { Drinks but not } \\
\text { until drunk } \\
\text { OR } 95 \% \mathrm{Cl}\end{array}$ \\
\hline \multicolumn{5}{|l|}{ Weekly disposable money } \\
\hline$€ 17$ or more & $14.58(6.82$ to 31.17$)$ & $9.01(6.25$ to 12.97$)$ & $3.47(2.80$ to 4.30$)$ & 1.95 (1.64 to 2.33$)$ \\
\hline$€ 10-€ 16$ & 10.84 (5.22 to 22.49$)$ & $7.79(5.54$ to 10.94$)$ & 3.62 (3.01 to 4.37$)$ & 1.90 (1.63 to 2.22$)$ \\
\hline$€ 7-€ 9$ & 4.75 (2.21 to 10.18$)$ & 5.45 (3.88 to 7.66$)$ & $3.10(2.58$ to 3.71$)$ & $1.99(1.72$ to 2.30$)$ \\
\hline$€ 5-€ 6$ & $1.96(0.88$ to 4.37$)$ & $3.19(2.28$ to 4.47$)$ & 2.22 (1.87 to 2.64$)$ & 1.56 (1.37 to 1.78$)$ \\
\hline$€ 3-€ 4$ & 0.60 (0.21 to 1.68$)$ & $1.90(1.33$ to 2.73$)$ & 1.65 (1.38 to 1.97$)$ & 1.37 (1.19 to 1.57$)$ \\
\hline$€ 2$ or less (reference) & 1 & 1 & 1 & 1 \\
\hline \multicolumn{5}{|l|}{ Place of residence } \\
\hline Metropolitan area & 1.27 (0.63 to 2.59$)$ & $1.09(0.78$ to 1.52$)$ & $1.13(0.92$ to 1.37$)$ & $1.00(0.85$ to 1.18$)$ \\
\hline Cities & 0.71 (0.35 to 1.43$)$ & $1.00(0.74$ to 1.35$)$ & $0.84(0.69$ to 1.01$)$ & $0.84(0.72$ to 0.97$)$ \\
\hline Towns & $1.00(0.54$ to 1.85$)$ & $1.19(0.91$ to 1.55$)$ & $0.97(0.83$ to 1.14$)$ & $0.85(0.75$ to 0.97$)$ \\
\hline Villages & 1.380 .74 to 2.59 & $1.13(0.85$ to 1.50$)$ & $1.06(0.90$ to 1.25$)$ & $0.97(0.85$ to 1.12$)$ \\
\hline Rural area (reference) & 1 & 1 & 1 & 1 \\
\hline \multicolumn{5}{|l|}{ Father's/guardian's education } \\
\hline Basic & $0.75(0.45$ to 1.26$)$ & $1.38(0.97$ to 1.96$)$ & $1.14(0.99$ to 1.32$)$ & $0.94(0.83$ to 1.06$)$ \\
\hline Secondary & $0.51(0.26$ to 1.00$)$ & 1.28 (1.01 to 1.62$)$ & $0.87(0.73$ to 1.04$)$ & $0.96(0.83$ to 1.10$)$ \\
\hline Tertiary (reference) & 1 & 1 & 1 & 1 \\
\hline \multicolumn{5}{|l|}{ Father's/guardian's professional status } \\
\hline Upper white collar & $0.44(0.25$ to 0.79$)$ & $0.94(0.74$ to 1.18$)$ & $0.92(0.80$ to 1.06$)$ & $1.04(0.92$ to 1.18$)$ \\
\hline Lower white collar & $1.02(0.67$ to 1.56$)$ & $1.03(0.84$ to 1.25$)$ & $1.03(0.91$ to 1.17$)$ & 1.05 (0.94 to 1.17$)$ \\
\hline Agriculture and forestry & $0.51(0.19$ to 1.35$)$ & $0.90(0.62$ to 1.30$)$ & $0.96(0.77$ to 1.19$)$ & 1.07 (0.89 to 1.27$)$ \\
\hline Blue collar (reference) & 1 & 1 & 1 & 1 \\
\hline \multicolumn{5}{|l|}{ Family structure } \\
\hline In a nuclear family & $0.38(0.26$ to 0.56$)$ & $0.47(0.39$ to 0.56$)$ & $0.63(0.55$ to 0.70$)$ & $0.86(0.77$ to 0.95$)$ \\
\hline Not in a nuclear family (reference) & 1 & 1 & 1 & 1 \\
\hline Girls & $\begin{array}{l}\text { Drunk weekly } \\
\text { OR } 95 \% \mathrm{Cl}\end{array}$ & $\begin{array}{l}\text { Drunk monthly } \\
\text { OR } 95 \% \mathrm{Cl}\end{array}$ & $\begin{array}{l}\text { Drunk } \\
\text { occasionally } \\
\text { OR } 95 \% \mathrm{Cl} \\
\end{array}$ & $\begin{array}{l}\text { Drinks but not } \\
\text { until drunk } \\
\text { OR } 95 \% \mathrm{Cl}\end{array}$ \\
\hline \multicolumn{5}{|l|}{ Weekly disposable money } \\
\hline$€ 17$ or more & $14.17(7.06$ to 28.48$)$ & $6.63(5.01$ to 8.78$)$ & $4.13(3.38$ to 5.05$)$ & $2.37(1.99$ to 2.84$)$ \\
\hline$€ 10-€ 16$ & 9.71 (5.12 to 18.42$)$ & 5.10 (4.02 to 6.47$)$ & $2.96(2.50$ to 3.50$)$ & 1.68 (1.46 to 1.94$)$ \\
\hline$€ 7-€ 9$ & 6.35 (3.32 to 12.16$)$ & 3.88 (3.06 to 4.91$)$ & 2.88 (2.45 to 3.39$)$ & 1.77 (1.54 to 2.04$)$ \\
\hline$€ 5-€ 6$ & 2.21 (1.10 to 4.44$)$ & 2.53 (2.01 to 3.18$)$ & 2.27 (1.95 to 2.64 & $1.60(1.41$ to 1.81$)$ \\
\hline$€ 3-€ 4$ & $1.67(0.82$ to 3.41$)$ & $1.29(1.00$ to 1.65$)$ & $1.63(1.40$ to 1.90 & $1.22(1.08$ to 1.39$)$ \\
\hline$€ 2$ or less (reference) & 1 & 1 & 1 & 1 \\
\hline \multicolumn{5}{|l|}{ Place of residence } \\
\hline Metropolitan area & $1.42(0.73$ to 2.77$)$ & $1.35(1.02$ to 1.78$)$ & $1.05(0.88$ to 1.26$)$ & $1.17(1.00$ to 1.37$)$ \\
\hline Cities & $1.12(0.58$ to 2.14$)$ & $1.26(0.97$ to 1.63$)$ & $0.91(0.77$ to 1.08$)$ & 0.91 (0.79 to 1.06$)$ \\
\hline Towns & $1.72(0.98$ to 3.04$)$ & 1.65 (1.31 to 2.08$)$ & $1.04(0.90$ to 1.21$)$ & $1.03(0.90$ to 1.17$)$ \\
\hline Villages & 1.04 (0.56 to 1.94$)$ & 1.57 (1.24 to 2.00$)$ & $1.13(0.97$ to 1.31$)$ & $0.99(0.87$ to 1.14$)$ \\
\hline Rural area (reference) & 1 & 1 & 1 & 1 \\
\hline \multicolumn{5}{|l|}{ Father's/guardian's education } \\
\hline Basic & 1.55 (0.96 to 2.50$)$ & $1.52(1.26$ to 1.84$)$ & 1.28 (1.12 to 1.45$)$ & $1.06(0.95$ to 1.19$)$ \\
\hline Secondary & $0.96(0.53$ to 1.74$)$ & 1.210 .96 to 1.51$)$ & $1.05(0.90$ to 1.22$)$ & $1.03(0.90$ to 1.18$)$ \\
\hline Tertiary (reference) & 1 & 1 & 1 & 1 \\
\hline \multicolumn{5}{|c|}{ Father's/guardian's professional status } \\
\hline Upper white collar & $0.51(0.31$ to 0.84$)$ & $0.77(0.64$ to 0.92$)$ & $0.95(0.84$ to 1.08$)$ & $1.07(0.95$ to 1.20$)$ \\
\hline Lower white collar & $0.95(0.66$ to 1.36$)$ & $0.93(0.79$ to 1.09$)$ & $0.98(0.87$ to 1.10$)$ & 1.01 (0.91 to 1.12$)$ \\
\hline Agriculture and forestry & $0.65(0.28$ to 1.49$)$ & $0.73(0.53$ to 0.99$)$ & $0.73(0.60$ to 0.90$)$ & 0.99 (0.84 to 1.18$)$ \\
\hline Blue collar (reference) & 1 & 1 & 1 & 1 \\
\hline \multicolumn{5}{|l|}{ Family structure } \\
\hline In a nuclear family & $0.28(0.21$ to 0.39$)$ & $0.42(0.36$ to 0.48$)$ & $0.53(0.47$ to 0.59$)$ & $0.71(0.64$ to 0.78$)$ \\
\hline Not in a nuclear family (reference) & 1 & 1 & 1 & 1 \\
\hline
\end{tabular}


Figure 2 The $\gamma$ coefficients and their $95 \%$ Cls for the associations between alcohol drinking and disposable income among 14-year-olds.

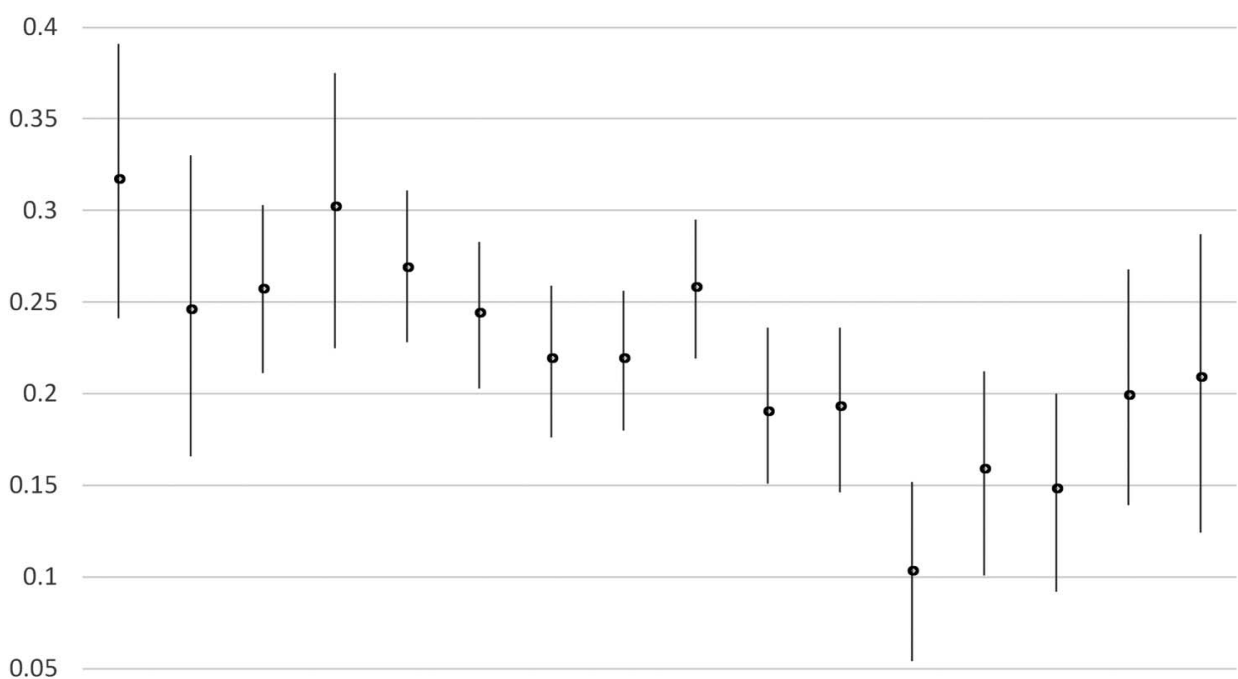
1983198519871989199119931995199719992001200320052007200920112013 severe through the whole drinking pattern spectrum from 1983 until the late 1990s, after which drinking became less prevalent. Disposable income among this age group increased twofold during the 30-year period. The alcohol drinking pattern was significantly associated with disposable income available to the adolescent. The OR for monthly drunkenness versus abstinence was 6.6 (95\% CI 5.0 to 8.8) among girls and 9.0 (6.3 to 13.0) among boys in the highest income group, receiving $€ 17$ per week or more when contrasted with the lowest income group that had $€ 2$ or less. Income seems to have been strongly associated with heavy drinking, which requires more money. The association was considerably more moderate for drinking small amounts; the ORs were under 3.0 for all income categories when compared with the lowest income group. Drinking large amounts of alcohol until drunk seemed more affected by period effects than drinking small amounts. Furthermore, the association between income and drinking pattern weakened considerably during the 30-year period. Considering similar observations on declining adolescent drinking in numerous other countries $^{13}$ and theoretical deliberations, ${ }^{16}$ it is likely that the findings on decreasing importance of disposable income available for adolescents to their drinking are generalisable to high-income countries.

The changes in time in the relationship between income and drinking alcoholic beverages are also affected by changes in beverage prices. The development of alcohol prices captured by the real price index indicated increasing average price of alcohol from the year 2000 until 2003, when it was 7\% more expensive than at the turn of the millennium. ${ }^{36}$ Owing to tax changes, prices then fell to $4 \%$ lower than in 2000; this again changed, both due to the global financial crisis and national tax increases, so that in 2013 alcohol was, on average, $28 \%$ more expensive than in the year 2000 .
Beer, the beverage favoured by the underaged who drink heavily, ${ }^{37}$ was $35 \%$ more expensive in real terms than in the year 2000. This figure is, in fact, very close to the corresponding increase in income among 14-year-olds in the same period. ${ }^{25}$ Thus, the affordability of alcohol among 14-year-olds did not change during the period.

Money has been presented as a key mediator between parents and adolescents. ${ }^{19} 38$ In the Nordic countries, 14-year-olds do not work in large numbers and their work income is relatively low. ${ }^{22}$ Thus, parents have had the means to control adolescent consumption, including alcohol drinking. Other parenting factors, ${ }^{15}$ however, complicate the picture. In Finland, a report published in 2007 observed that parental control over their offsprings' alcohol use had not tightened. ${ }^{17}$ Subsequent papers from Finland witnessed a gradual tightening of parental attitudes towards adolescent drinking, ${ }^{14} 18$ alcohol-related parenting practices ${ }^{39}$ and control of selling alcoholic beverages to minors. ${ }^{18} 40$ Similar observations from other countries include tightening of alcohol-specific parenting practices between the years 2007 and 2011 in the Netherlands, ${ }^{41}$ which was shown to be associated with decreased drinking among those under 16 years of age, and parental supervision being associated with lesser drinking among 11-year-olds in the $\mathrm{UK}^{42}$

Alcohol drinking is also affected by period-related or cohort-related factors. ${ }^{43}$ This paper makes an attempt to unveil the cohort effects: the fact that changes in the surrounding society affect people of different ages in different ways, creating commonalities of individuals. Cohort effects were identified using this same data set in Finland: ${ }^{6}$ contextual factors contributed more to the development of drunkenness than drinking small amounts. One possible explanation for our results can be that recent cohorts are more interested in other ways 
of spending time and money, for example, using digital technology, than in drinking, especially to drunkenness.

On the basis of survey data from 2006 in Finland, alcoholic beverages do not seem to be a priority on the list of possible ways to spend money. ${ }^{44}$ Boys aged 11-17 years reported that they prefer to spend their income on sweets, digital games, mobile phones and hobbies, while same-aged girls prioritised sweets, clothing, mobile phones and going out to cafes, for example. Alcohol and tobacco were the eighth item on both genders' lists. Unfortunately, no time trend information exists on adolescent consumption preferences. Since the turn of the millennium, spending of income on alcoholic beverages has met with new competition from, for example, digital gaming and other amusement and pastime activities, including sports, ${ }^{45}{ }^{46}$ which are not readily compatible with drinking alcohol. We can only speculate that the observed weakening connection between income and alcohol drinking in the recent decade may reflect a change in the importance of alcohol in teenagers' consumption-it may have been partly replaced by spending on digital technology. Parental control of income does not seem an efficient way of controlling alcohol drinking; emphasis may need to be directed towards ensuring that teenaged adolescents spend their time and energy on more constructive activities than simply hanging out.

The indicators have been derived from mailed selfreport surveys and are subject to measurement biases. However, the best possible care was taken to ensure comparability across the study years; for example, regarding the timing, questions and sampling remained unchanged throughout the years. The response rate was good until recent years; however, it was down to $38 \%$ in 2013. In order to increase the response, the option to participate using the internet was introduced in 2009; around 50\% of the responses have since been received via the internet. While even in 2013 the rate remained $46 \%$ among girls, the response rate of only 30\% among boys in 2013 means that the results concerning boys in recent years must be judged with caution. In analyses based on response timing and test-retest subsamples, it has been concluded that while it is likely that the prevalence of alcohol use is equal among respondents and nonrespondents, drinking until drunk is more common among non-respondents. ${ }^{43}$ Similar conclusions were drawn from comparisons with the School Health Promotions Survey (SHPS), which is a nationally representative classroom survey with around a $90 \%$ response rate. ${ }^{47}$ The rates of abstention for 14-16 years old, for example, were $27 \%$ (AHLS) and for 15-16 years old 25\% (SHPS) in the year 2001, and 52\% (AHLS) and 50\% (SHPS) in the year 2013. ${ }^{48}$ Owing to the declining response and respondent selection based on drinking habits, it is likely that the figures presented here concerning drunkenness among 14-year-olds are slightly underestimated, especially after the year 2009. Since study drop-out was more pronounced among heavier drinkers, the decrease in the association between income and drinking patterns may be affected such that the decrease in the strength of association is overestimated. However, the selection bias is most likely not enough to influence the general decreasing trend such that it would be an artefact. Unfortunately, non-response analysis for disposable income is not available in this study, and no 14-year-olds' income trends have been published from other adolescent data set, either. School-based survey data with an average yearly response rate of around $90 \%$ show a trend of increasing disposable income for 15-16 years old between the years 1995 and $2011,,^{39}$ in good agreement with the figures presented in this paper.

The two sensitivity analyses, one testing for sensitivity to income distribution changes and the other for sensitivity to alcohol price changes, showed that the results were robust to these two possible explanations/confounders. It is likely that price is, however, a significant issue at the time of purchase, and the prices 14-year-olds are forced to pay for acquiring alcohol illegally may be higher than the average retail price. Unfortunately, information on this phenomenon was not available for the analyses. In addition, while alcohol availability is certainly a significant factor in underaged drinking, valid indicators for the experienced availability at the individual level were not available for analyses.

The decreases in adolescent drinking similar to the ones reported here for Finland have raised research interest in many other high-income countries ${ }^{13}$ and a decline in 11-15 years old drinking between the years 2002 and 2010 has been observed in 20 of the participating 28 countries. A range of explanations for this phenomenon have been speculated on, including income changes, teen culture changes, stricter legal enforcement, changes in adult drinking and adult attitudes towards adolescent drinking, as well as policy and prevention aimed at decreasing drinking. ${ }^{12} \quad 13 \quad 16 \quad 49$ Empirical evidence on the decrease in 14-17 years old drinking observed recently in Australia shows the phenomenon to be distributed across all socioeconomic subsections of the population examined. ${ }^{12}$ Of the hypotheses and evidence reviewed recently in the UK, the declining alcohol affordability and better parenting were seen as the most credible explanations for declining youth drinking. ${ }^{16}$

\section{CONCLUSIONS}

It is just as important to identify factors behind recent decreases in adolescent drinking as it is to analyse past increases in drinking. The factors causing the downturn can be used in future alcohol policies and interventions, ${ }^{3}$ as well as in developing public policies and action in general. In contrast with the clear effects of alcohol policy changes in consumption in the adult population, ${ }^{1}$ policy measures including tax changes do not seem to have had a noticeable influence on alcohol drinking or even drunkenness among the underaged in Finland. ${ }^{8}$ 
The current analyses further complicate the picture: a previously identified predictor of adolescent alcohol use, disposable income, has decreased in importance, and the influence of pocket money, which has been an important instrument for the parents to influence their children's alcohol drinking, seems to have weakened over the years.

Contributors Both authors jointly conceived of the study idea and design, as well as participated in the analysis of the data and interpretations of the results. TL wrote the first draft, which was then critically revised by both authors. The final version of the manuscript was approved by both authors.

Funding The data collection was funded by the Ministry of Social Affairs and Health (Finland).

Competing interests None declared.

Ethics approval Ethics Committee of the Tampere region (Finland).

Provenance and peer review Not commissioned; externally peer reviewed.

Data sharing statement Data set available on request from the University of Tampere, School of Health Sciences, Tampere, Finland.

Open Access This is an Open Access article distributed in accordance with the Creative Commons Attribution Non Commercial (CC BY-NC 4.0) license, which permits others to distribute, remix, adapt, build upon this work noncommercially, and license their derivative works on different terms, provided the original work is properly cited and the use is non-commercial. See: http:// creativecommons.org/licenses/by-nc/4.0/

\section{REFERENCES}

1. Babor TF, Caetano R, Casswell S, et al. Alcohol: no ordinary commodity: research and public policy. Oxford: Oxford University Press, 2010.

2. Wagenaar AC, Salois MJ, Komro KA. Effects of beverage alcohol price and tax levels on drinking: a meta-analysis of 1003 estimates from 112 studies. Addiction 2009;104:179-90.

3. Pennay A, Livingston M, MacLean S. Young people are drinking less: it is time to find out why. Drug Alcohol Rev 2015;34:115-18.

4. Lintonen T, Rimpelä M, Vikat A, et al. The effect of societal changes on drunkenness trends in early adolescence. Health Educ Res 2000;15:261-9.

5. Lintonen T, Wilska T, Koivusilta L, et al. Trends in disposable income among teenage boys and girls in Finland from 1977 to 2003. Int J Consum Stud 2007;31:340-8.

6. Lintonen T, Härkönen J, Raitasalo K, et al. Decreasing adolescent drinking: is there evidence for continuation onto future adult cohorts? APC-analysis of adolescent drinking in Finland, 1983-2013. Scand J Public Health 2016. doi:10.1177/ 1403494816665505. [Epub ahead of print 26 Aug 2016]

7. Kinnunen JM, Lindfors P, Pere L, et al. The Adolescent Health and Lifestyle Survey 2013. Adolescent smoking, alcohol and substance use in 1977-2013. Helsinki: Ministry for social affairs and health, 2013.

8. Lintonen T, Karlsson T, Nevalainen J, et al. Alcohol policy changes and trends in adolescent drinking in Finland from 1981 to 2011. Alcohol Alcohol 2013;48:620-6.

9. Health and Social Care Information Centre. Statistics on alcohol: England. London: Office of National Statistics, 2008.

10. Johnston L, O'Malley PM, Bachman JG, et al. Monitoring the future - national survey results on drug use, 1976-2012, Vol. 1, secondary school students. Ann Arbor: Institute for Social Research, University of Michigan, 2013.

11. Raninen J, Livingston $\mathrm{M}$, Leifman $\mathrm{H}$. Declining trends in alcohol consumption among Swedish youth-does the theory of collectivity of drinking cultures apply? Alcohol Alcohol 2014;49:681-6.

12. Livingston M. Trends in non-drinking among Australian adolescents. Addiction 2014;109:922-9.

13. Looze MD, Raaijmakers Q, Bogt TT, et al. Decreases in adolescent weekly alcohol use in Europe and North America: evidence from 28 countries from 2002 to 2010. Eur J Public Health 2015;25(Suppl 2): 69-72.
14. Raitasalo K, Holmila M. Alkoholinkäyttötapojen periytyminen ja vanhempien kasvatuskäytännöt" [Heritability of alcohol use patterns and the parental educational practices]. In: Lammi-Taskula, J, Karvonen S. eds. Lapsiperheiden hyvinvointi 2014 [The well-being of families with children 2014]. Helsinki: National Institute for Health and Welfare, 2014:196-204.

15. Ryan SM, Jorm AF, Lubman DI. Parenting factors associated with reduced adolescent alcohol use: a systematic review of longitudinal studies. Aust N Z J Psychiatry 2010;44:774-7.

16. Bhattacharya A. Youthful abandon-Why are young people drinking less? London: Institute of Alcohol Studies, 2016.

17. Karlsson T, Raitasalo K, Holmila M. Alaikäisten alkoholihankintojen sietämätön helppous [The unbearable ease of access to alcohol among adolescents]. In: Tigerstedt C. ed. Nuoret ja alkoholi [Youth and alcohol]. Helsinki: The Finnish Society for Alcohol and Drug Research \& Finnish Youth Research Society, 2007:149-160.

18. Raitasalo K, Huhtanen $P$, Ahlström $S$. Nuorten päihteiden käyttö sekä käsitykset niihin liittyvistä riskeistä ja saatavuudesta Suomen ESPAD-aineiston tuloksia 1995-2011 [The use of intoxicants and perceptions of risk and availability based on the ESPAD Data in Finland 1995-2011]. Yhteiskuntapolitiikka 2012;77:72-80.

19. Brusdal R, Berg L. Are parents gender neutral when financing their children's consumption? Int J Consum Stud 2010;34:3-10.

20. West $\mathrm{P}$, Sweeting $\mathrm{H}$, Young $\mathrm{R}$, et al. A material paradox: socioeconomic status, young people's disposable income and consumer culture. J Youth Stud 2006;9:437-62.

21. Besen-Cassino $Y$. The cost of being a girl: gender earning differentials in early labor markets. NWSA J 2008;20:146-60.

22. Danske Bank. Financial literacy among 15-17 year-old teenagersbased on a market research survey among teenagers 15-17 years old in Denmark, Norway, Sweden and Finland. Copenhagen: Danske Bank corporate report, 2013.

23. de Lange M, Gesthuizen M, Wolbers MHJ. "Youth labour market integration across Europe". Eur Soc 2014;16:194-212.

24. Mortimer JT. The evolution, contributions, and prospects of the youth development study: an investigation in life course social psychology. Soc Psycholy Q 2003;75:5-27.

25. Wilska T, Lintonen T. The gender gap in teenagers' incomes. A 30-year trend in Finland 1983-2013. J Youth Stud 2015;19: 421-37.

26. Kooreman P. Time, money, peers, and parents; some data and theories on teenage behavior. J Popul Econ 2007;20:9-33.

27. Raijas A, Wilska T. Huolenpitoa ja jakamista-rahan ja ajan jakautuminen suomalaisissa lapsiperheissä [Caring and sharingthe allocation of time and money in households]. Discussion and working papers 104/2007. Helsinki: National Consumer Research Center, 2007.

28. Melotti R, Heron J, Hickman M, et al. Adolescent alcohol and tobacco use and early socioeconomic position: the ALSPAS birth cohort. Pediatrics 2011;127:e948-955

29. Richter M, Leppin A, Gabhainn S. The relationship between parental socio-economic status and episodes of drunkenness among adolescents: findings from a cross-national survey. BMC Public Health 2006;6:289.

30. Kuntsche E, Rossow I, Simons-Morton B, et al. Not early drinking but early drunkenness is a risk factor for problem behaviors among adolescents from 38 European and North American Countries. Alcohol Clin Exp Res 2012;37:308-14.

31. Samposalo H. Relationship between drinking pattern and alcohol-related harms and risk behaviors among 14- to 16-year-old adolescents in Finland. Tampere: Tampere University Press, 2013.

32. Lintonen T, Ahlström S, Metso L. The reliability of drinking self-reports in adolescence. Alcohol Alcohol 2004;39:362-8.

33. Lintonen $\mathrm{T}$, Rimpelä M. The validity of the concept of 'self-perceived drunkenness' in adolescent health surveys. J Subst Use 2001;6:145-50.

34. Agresti A. Categorical data analysis, third ed. New York: Wiley, 2012.

35. International Labour Organisation. International Standard Classification of Occupations. Geneva: International Labour Office, 1990.

36. Official Statistics of Finland. Yearbook of alcohol and drug statistics 2015. Helsinki: National Institute for Health and Welfare, 2015.

37. Lintonen T, Konu A. Drunkenness-related alcoholic beverage choices among adolescents. J Subst Use 2001;6:16-21.

38. Schor JB. Born to buy: the commercialized child and the new consumer culture. New York: Scribner, 2004.

39. Raitasalo K, Holmila M. Practices in alcohol education among Finnish parents: Have there been changes between 2006 and 2012? Drugs Educ Prev Pol, 2016. doi: 10.1080/ 09687637.2016.1183587. [Epub ahead of print 1 Jun 2016]. 
40. Holmila M, Warpenius K, Warsell L, et al. Local alcohol policy. Final report of the PAKKA project. Helsinki: National Institute for Health and Welfare, 2009.

41. de Looze M, Vermeulen-Smit E, ter Bogt TF, et al. Trends in alcohol-specific parenting practices and adolescent alcohol use between 2007 and 2011 in the Netherlands. Int J Drug Policy 2014:25:133-41.

42. Kelly $\mathrm{Y}$, Goisis A, Sacker A, et al. What influences 11-year-olds to drink? Findings from the Millennium Cohort Study. BMC Public Health 2016;16:169.

43. Kerr WC, Greenfield TK, Bond J, et al. Age, period and cohort influences on beer, wine and spirits consumption trends in the US National Alcohol Surveys. Addiction 2004;99:1111-20.

44. Wilska T. Tytöt, pojat ja talous [Girls, boys and economy]. In: Halko ML, Mikkola A, Ruuskanen OP. eds. Naiset, miehet ja talous [Women, men and economy]. Helsinki: Gaudeamus, 2011:119-137.
45. Pääkkönen H. Mihin koululaisten aika kuluu? [How do school-children spend their time?]. Soc Stat Rev 2002;4:2-9.

46. Raitasalo K, Simonen J. Alaikäiset juovat entistä vähemmän, mutta nuorten aikuisten juominen lisääntyy [The under-aged drink less but drinking increases among young adults]. Yhteiskuntapolitiikka 2011;76:17-29.

47. Raisamo S, Pere L, Lindfors $\mathrm{P}$, et al. Nuorten terveystapatutkimus 2011-Nuorten tupakkatuotteiden ja päihteiden käyttö 1977-2011 [The Adolescent Health and Lifestyle Survey 2011. Adolescent smoking, alcohol and substance use in 1977-2011]. Helsinki: Ministry of social affairs and health, 2011.

48. https://www.thl.fi/fi/web/thlfi-en/research-and-expertwork/populationstudies/school-health-promotion-study [referenced 10 Nov 2016]

49. Anderson P, Møller L, Galea G. Alcohol in the European Union. Consumption, harm, and policy approaches. Copenhagen: WHO Regional Office for Europe, 2012. 